\title{
DISPARITIES IN MUNICIPAL WASTE MANAGEMENT ACROSS EU-27. A GEOGRAPHICAL APPROACH
}

\author{
Florin-Constantin Mihai ${ }^{1}$, Liviu Apostol ${ }^{2}$
}

Key words: territorial disparities, municipal waste, spatial-temporal analysis

\begin{abstract}
Inadequate waste management leads to many environmental issues and the adoption of an efficient and sustainable waste management has become a priority objective of the EU. However, besides the demographic factors, the various socio-economic and geographical conditions of this complex space lead to major disparities in municipal waste management between North and South, East and West. This paper aims to do a spatial-temporal analysis of the Eurostat indicators using ascending hierarchical cluster analysis that divides the member states into five typological classes. The resulted maps highlight territorial disparities among Member States on municipal waste management and also reveal the evolution of environmental policies between 2003-2009 related to the EU acquis.
\end{abstract}

\section{Introduction}

Municipal waste and similar are the waste generated in urban and rural areas respectively: in households (household waste), commerce and trade, small businesses, offices and institutions, (similar waste), yard and parks waste, bulky waste, street waste, construction and demolition waste. As far as municipal waste is concerned, the differences between countries arise for two main reasons: the differences found in specific categories to be included in this stream (the most relevant being 'household' and 'similar' waste, from shops, offices, etc.) and the differences found in the collection system applied in each country. (Eurostat, 2001) The share of waste from households ranges for most countries between $60 \%$ and $90 \%$ depending on the amount of other waste collected under the responsibility of the municipality, the percentage of commercial waste in municipal waste ranges for most countries between $10 \%$ and $35 \%$. (EC, 2005).

Europe has more experience with waste prevention than other regions, and recycling and materials recovery are well supported in Northern Europe. This is much less true in the southern EU countries and in the transition economies of the

\footnotetext{
${ }^{1} \mathrm{PhD}$ student "Alexandru Ioan Cuza" University, mihai.florin86@yahoo.com

2 Prof.PhD ”Alexandru Ioan Cuza" University, apostolliv@yahoo.com
} 
Eastern Europe (UNEP, 2005). Household waste management schemes adopt economic, regulatory or incentive based instruments that are widely acceptable across Europe (Husaini et al., 2007). One person's waste can be a resource to others, particularly in different geographical, temporal and cultural contexts (Davies, 2003). Though waste prevention is at the top of the EU waste hierarchy, waste management (separate collection) and landfill limitation policies have prevailed, if not dominated the field (Mazzanti and Zoboli, 2008).

Improving household waste management behaviour has been identified as an important component of reducing the volume of the produced waste. (Fahy and Davies, 2007)

\section{Materials and methods}

This article proposes a geographical approach to highlight territorial disparities in the EU-27 on municipal waste generation, municipal waste disposal (landfilling and incineration), recycling and composting. Changing methodologies concerning waste statistics since 2001 and the implementation of the EU acquis in the new EU member states have led to a progressive improvement of quality data on municipal waste management. However, a spatial-temporal analysis requires caution because the relevance of these data is questionable and leads to difficulties in interpreting the results. Thus, the period chosen for such an analysis is 2003 2009, although the Eurostat database contains available data since1995. We have to take into account that in the new Member States, on the one hand the population is not fully covered by sanitation services and on the other hand, the reported values are estimated. Often these data are calculated according to the volume of waste or applying general indicators of waste generation for the population unserved by sanitation services. Moreover, the differences among countries on waste fractions that are included in the category of municipal waste slow down the geographic analysis of waste management. The introduction of weight systems in waste management facilities and the increasing access to sanitation services lead to improved waste indicators.

In this context, the spatial-temporal analysis takes into account the following indicators: municipal waste generation ( $\mathrm{kg} /$ inhabitant / year), landfilled waste $(\mathrm{kg}$ / inhabitant / year) incinerated waste (kg / inhabitant / year). For each indicator, statistics are processed using ascending hierarchical cluster analysis that divides the member states in five typological classes that are mapped. Each class has different values (standard deviations) related to the EU-27 average, allowing deduction of qualitative conclusions. The charts are designed to support the maps obtained and to facilitate the interpretation of results. In order to assess the current systems of municipal waste management, an ascending hierarchical cluster analysis regarding the share $(\%)$ of landfilled, incinerated, recycled and composted waste of the total 
municipal waste generated in 2009 (the last Eurostat available data, updated in 2011) is achieved.

\section{Results and discussion}

\subsection{Spatial-temporal analysis of municipal waste generation}

The indicator of municipal waste generation per capita is particularly important in planning actions for a sustainable waste management. It is also the basis of references for forecasting and modeling future waste generation in correlation with different economic and socio-demographic parameters (Beigl et al., 2008). Applying ascending hierarchical cluster analysis, the EU-27 members were divided in the following typological classes:

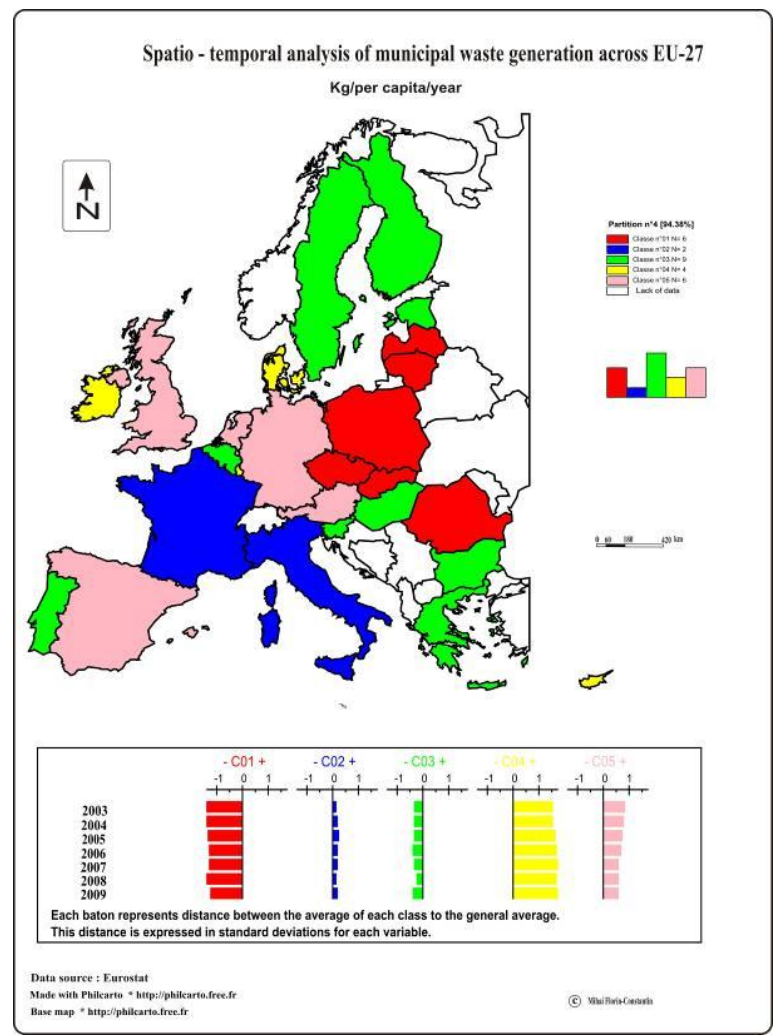

Fig.1 - Disparities in the municipal waste generation in the EU-27

Class 1- includes most new member states of the EU, municipal waste generation per capita is significantly lower (300 kg/per capita/yr) than the EU-27 
due to increased disparities on the economic situation and standard of living. The multi-annual average of GDP per capita <100 (in PPS EU27 = 100); urban population is lower and life expectancy as well. Low values for these countries are explained by the fact that the population is only partially served by sanitation services and waste quantities are usually estimated and not weighed due to the lack of infrastructure in this regard.The trend of a slight increase in waste generated since 2004 is due on the one hand to the improvement of waste statistical methodology and development of waste collection services and on the other hand to the economic growth, which stimulates the consumption patterns.

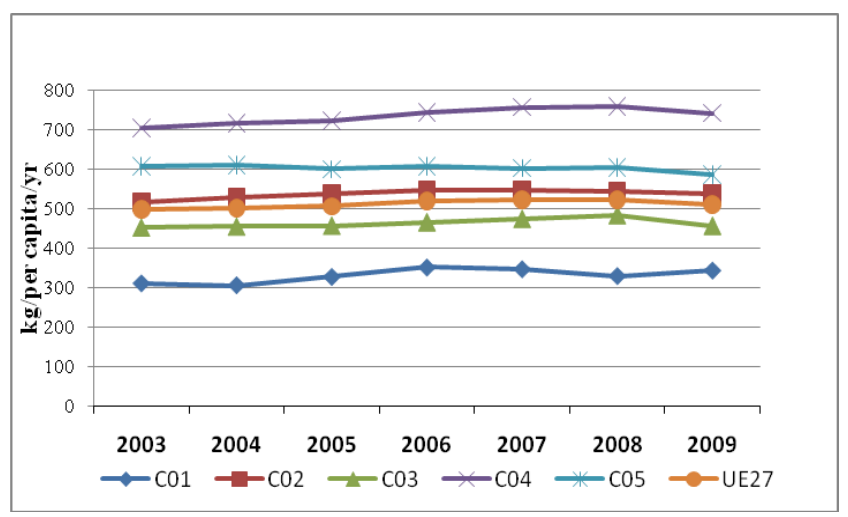

Fig. 2 - Municipal waste generated - the annual average of classes compared with the EU-27 average

Class 2 - France and Italy have waste generation values very close to the EU -27 average (over $500 \mathrm{~kg} /$ per capita/yr) and a chronological evolution approximately constant from 2003 to 2009 . This shows that the primary waste management measures were oriented to waste disposal and less to recovery or prevention of waste generation.

Class 3- per capita waste generation is lower than the EU-27 average (400$500 \mathrm{~kg} /$ per capita/yr); the data for Hungary, Slovenia and Bulgaria have improved since 2002 with their harmonization with the EU legislation; however, precautions are necessary in their interpretation. Also in Portugal, since 2001, conditions have been created to obtain more reliable data at national level (Magrinho A et al. 2006). Prevention and waste reduction policy is poorly implemented and recycling has a low efficiency.

In Estonia, the share of similar (commercial) waste is higher than household waste (EC, 2005). The quantity of solid waste generated in Greece continues to be somewhat lower than in other European countries, reflecting less intense 
consumption patterns (Papaioannou and Economopoulou, 2004). In the Northern Europe countries (Sweden and Finland), although they generate less waste than the EU-27 average, the values are high compared to low population densities. So far, in Finland, the national targets on MSW reduction have been set fairly low. (Sokka et al 2007)

Class 4-. Includes on the one hand the states with the highest living standards in Europe (Denmark and Luxembourg) and on the other hand Ireland and Cyprus where consumption growth in recent years have led to significant increasing of waste generation, higher than the EU 27 average (over $700 \mathrm{~kg} /$ per capita /yr) with a continuous ascending trend. Denmark policies focused on changing the method of waste disposal from land filing to incineration with energy recovery, supplemented by recycling programs measures and less on instruments which encourage waste prevention or reduction. Municipal waste management policy in Ireland has stimulated the increasing quantities of waste generated, far beyond EU average, due to the growing consumption. Opposition to charges on waste treatment and landfilling and low prevention and recycling programs have led to this situation.

(Davies, 2005). Cyprus, with a population of 949 000, generates waste far above the average of the EU-27, including waste from tourists, having only a $3 \%$ recycling rate. (Athanassiou and Zabaniotou, 2007)

Class 5-This class is represented by high-income countries Netherlands, Germany, Austria, above the EU 27 average (GDP> 100 in PPS for EU $27=100$ ), public access to waste collection services is $100 \%$, (OECD, 2008) waste management systems are based on incineration, recycling and waste recovery. In the UK, waste management is changing from waste disposal to recycling. After 2003 , there has been a slight decrease in waste generation that is due to economic instruments (charges on landfills or on the amount of waste generated), financial incentives for the private sector, the legal framework which aims to reduce waste generation. Unlike these countries, waste management policy in Spain was more oriented towards waste disposal in landfills. The high values are due to the progressive growth of the economy favoring consumption growth.

\subsection{Spatial-temporal analysis of municipal waste landfilled}

Waste landfilling is still an important option in waste management systems, but its share varies across the EU -27, emphasizing the following categories:

Class 1 - EU high-income countries, which can afford to dispose the municipal waste generated in incinerators equipped with facilities which ensure energy recovery and limit the environmental impact. Furthermore, the lower proportion of biodegradable waste and also the cooler climate favor the incineration and not the landfilling for Northern Europe (Denmark, Sweden). 
Landfill of waste is diminished due to legal regulations and economic instruments adopted (high charges for waste disposal facilities), waste incineration, biological and mechanical treatment and recycling programs being economically viable alternatives for Germany, Austria, Netherlands and Belgium. In Germany, waste disposal decreased significantly in recent years due to the improved recovery and recycling programs (Dongqing et al, 2010). The amount of waste landfilled per capita continuously decreases, suggesting the performances of waste management systems implemented in each state.

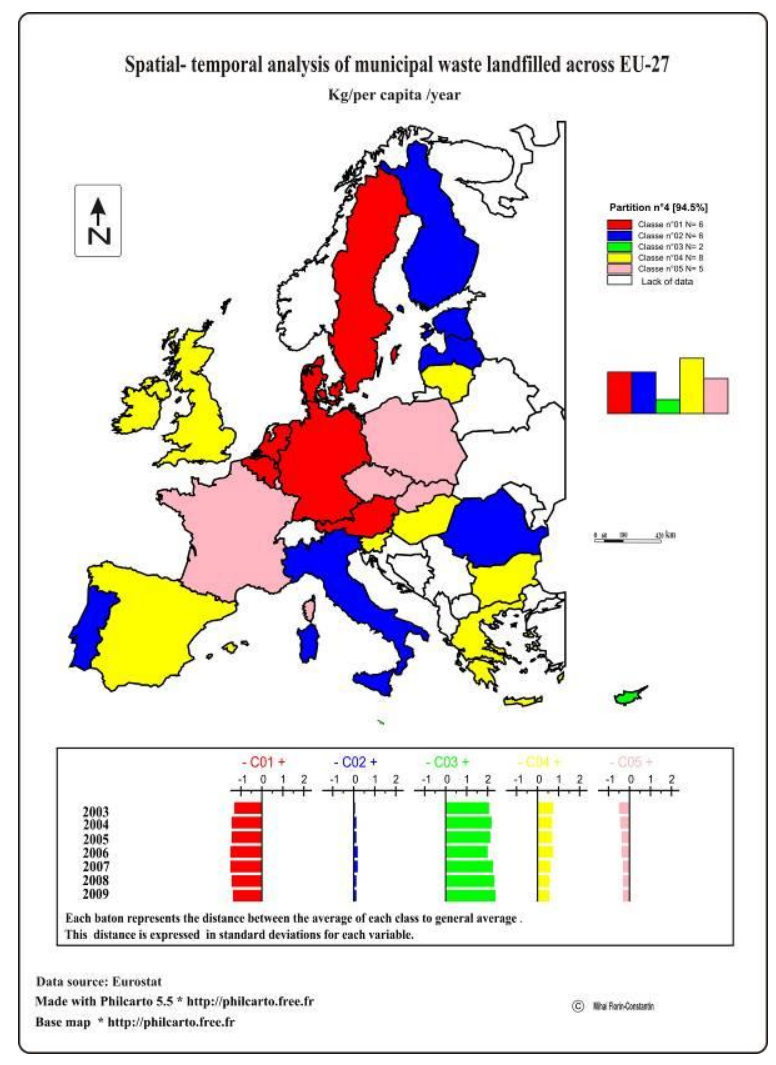

Fig.3 - Disparities in municipal waste landfilled

Class 2- Includes the new Member States where most of the generated waste is landfilled (Romania, Lithuania, Estonia), the southern states where the landfiling still has an important role in waste management options along with waste recycling and composting (Italy and Portugal) and Finland, where incineration is not as well developed as in Denmark or Sweden. 


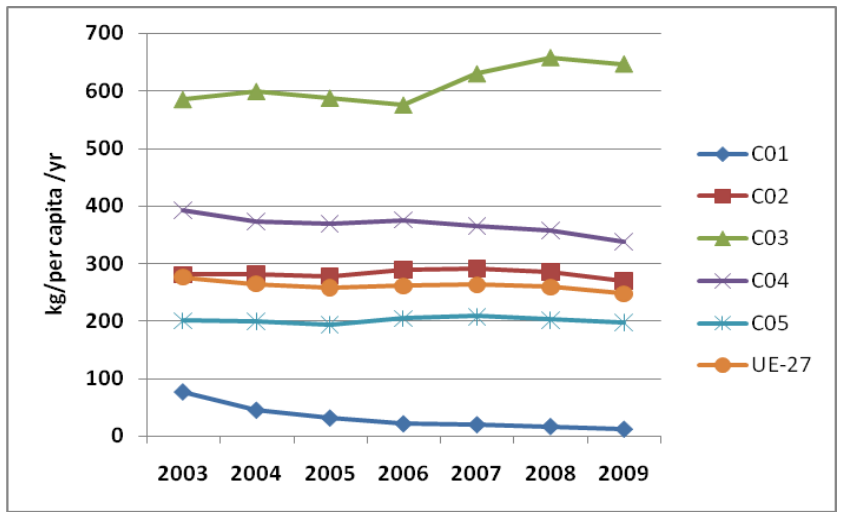

Fig.4 - Municipal waste landfilled - the annual average of classes compared with EU-27 average

Class 3 - Landfill of waste significantly above the EU-27 average with double values (over $600 \mathrm{~kg}$ / inhabitant / year) for the island states Malta and Cyprus with an ascendant trend since 2006. This is caused by the increased municipal waste generation, far above the EU average (fig.1), due to consumption growth and tourist inflows and on the other hand to the lack of measures to minimize their generation.

Class 4 - Most of the waste generated and collected is directly disposed in landfills (Bulgaria, Hungary, Slovenia, Lithuania) and recycling is poorly developed. Grecce depends strongly on sanitary landfills, although the need for increased recycling and new waste management facilities is recognized by the authorities in the Regional Plan. (Perkoulidis et al, 2010). The adoption of the acquis communautaire leads to an improvement in waste management. The focus is on alternative solutions regarding disposal of waste, for example replacement of non-compliant sites with sanitary landfills, construction of transfer stations or incinerators with energy recovery. The waste prevention measures implemented so far are not significant and the amounts of waste generated and landfilled are expected to increase in the future.

Class 5 - Landfill of waste is done under the EU-27 average (respectively $200 \mathrm{~kg} /$ per capita/yr), but it has the largest share in the treatment of waste generated for the Czech Republic, Slovakia and Poland. In Poland, the registered quantities of waste collected and disposed of are often deliberately underestimated, as a result of informal trading between the involved companies. (Den Boer et al., 2010).

In France, the need of landfills decreases because the waste management plans support the development of incineration plants and recycling facilities. 


\subsection{Spatial-temporal analysis of municipal waste incineration}

The incineration of municipal waste is often more expensive than waste landfilling, not being economically viable for the Southern and Eastern Europe. Also the higher share of biodegradable waste and lower amounts of waste generated encourage the waste landfilling and composting. Thus, in some Member States there are no incineration plants for municipal waste disposal (Romania, Bulgaria, Lithuania, Cyprus, Greece), but only for the industrial waste sector. The EU-27 average of incinerated municipal waste does not include these countries; the disparities are outlined by the following classes:

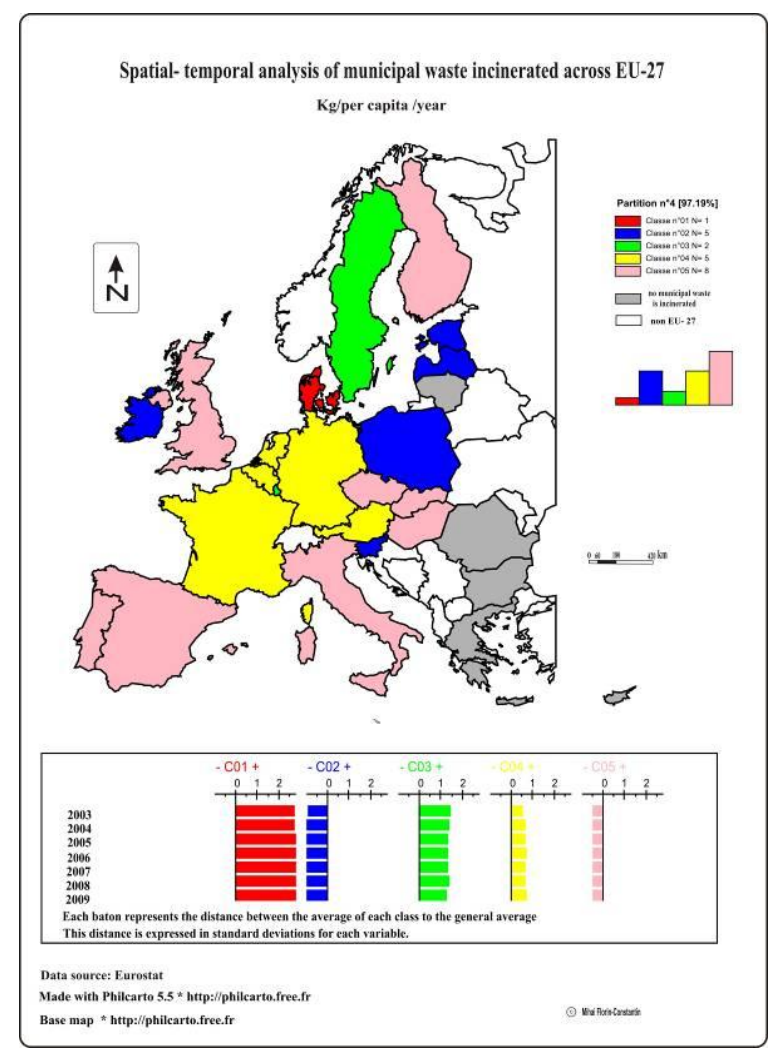

Fig.5 - Disparities in incinerated municipal waste

Class 1 - Since 2001, Denmark benefits from modern infrastructure able to meet the specific needs of waste incineration in terms of environmental protection (Burcea, 2009). Also Denmark generates large amounts of waste $(600 \mathrm{~kg} / \mathrm{per}$ 
capita / yr): 2/3 is incinerated (about $400 \mathrm{~kg} /$ per capita / yr), the rest is recycled or treated; landfilling is almost inexistent.

Class 2 - includes countries where municipal waste incineration takes place in pilot programs or is in its early stages with very low amounts per capita $(<10$ $\mathrm{kg} /$ per capita/yr) compared to the EU-27 average, and the landfill of waste prevails.

Class 3 - Sweden has developed facilities on municipal waste incineration, the amount of incinerated waste is of $250 \mathrm{~kg} /$ per capita/yr, far above the EU-27 average $(100 \mathrm{~kg} / \mathrm{per}$ capita $/ \mathrm{yr})$.

Class 4 - includes high-income countries with a modern infrastructure on municipal waste management. Waste incineration is above the EU-27 average (150 $\mathrm{kg} /$ per capita/yr), waste landfilling is limited for recycling or mechanical-biological treatment.

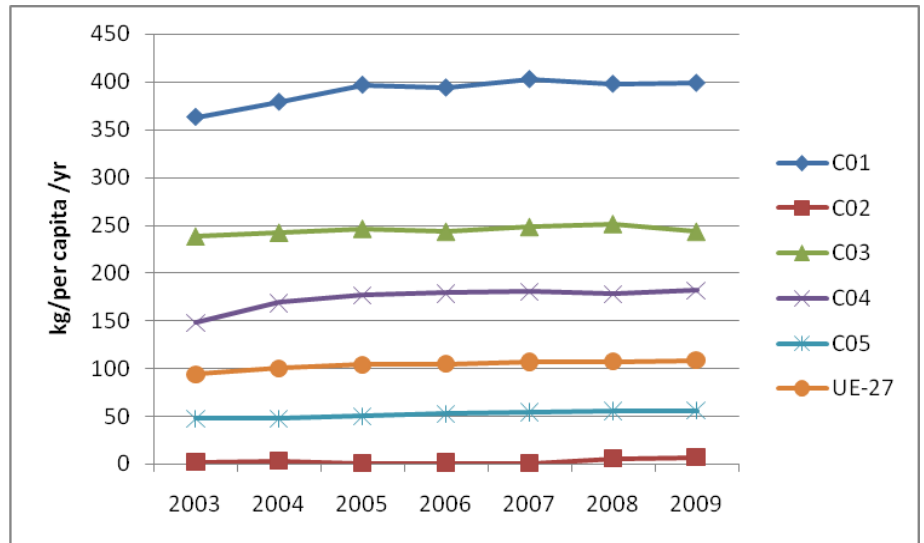

Fig.6 - Municipal waste incinerated - the annual average of classes compared to the EU-27 average

Class 5 - countries where municipal waste incineration is developing against landfill of waste (Finland, UK), the incinerated municipal waste is half of the EU27 average respectively $50 \mathrm{~kg} / \mathrm{per}$ capita/yr). In Italy, there are regional disparities regarding waste management issues. (Mengozzi, 2010). The incineration plays an important role in waste management options in the industrial regions from the North, unlike the Central and Southern Italy, where waste landfilling is the main method of waste treatment causing governance issues (e.g. the Naples case).

\subsection{Current municipal waste management options across the EU-27}

Class 1 - includes the countries where waste landfilling has become insignificant, being replaced by incineration with energy recovery (Denmark, 
Sweden), co-incineration, recycling and composting having a significant share in waste management options in Belgium, Holland, Germany and Austria. These Member States have the most advanced waste management systems of the EU-27.

Class 2 - new EU members of Central and Eastern Europe, where waste landfilling is still the main choice in waste management, recycling and composting of waste is in its early stages; these countries have difficulties in the implementation of the EU acquis.

Class 3 - states which have developed composting facilities for biodegradable waste; recycling is not very developed and waste landfilling still prevails.

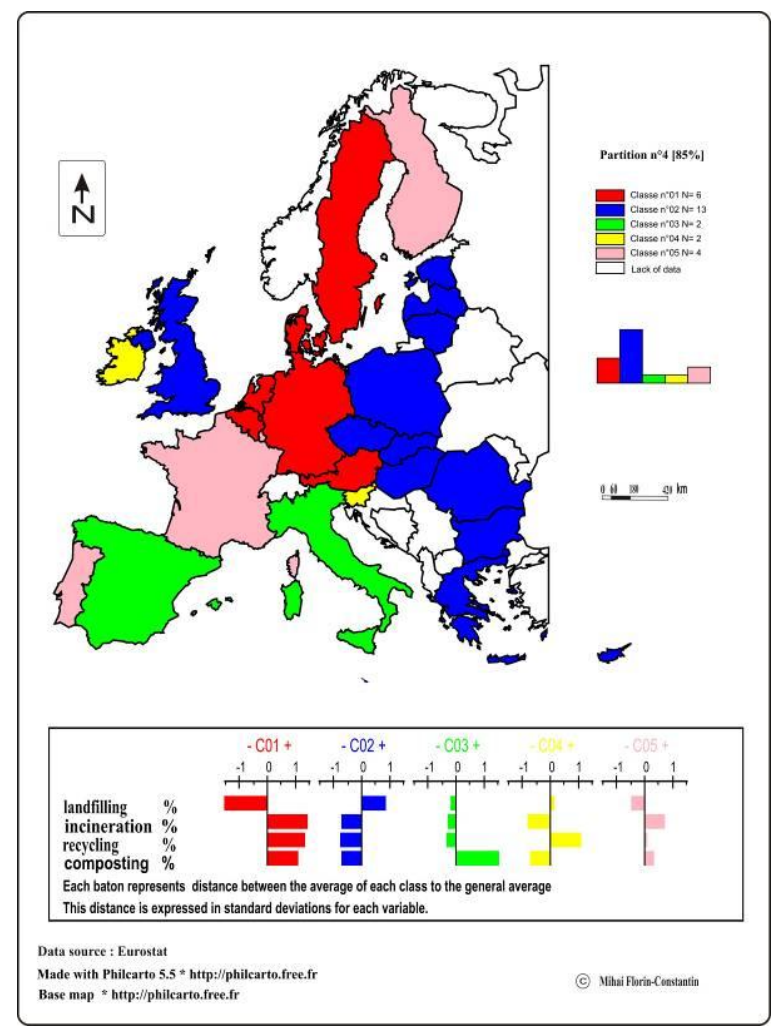

Fig. 7 - Disparities in current waste management systems in the EU-27

Class 4 - waste landfilling is still significant, but improvements were noted on the development of recycling programs in recent years, in Ireland and Slovenia. 
Class 5 - the share of incinerated waste increases over the EU average and the amount of landfilled waste decreases (Finland, France); waste recycling and composting have an important role in waste management systems.

\section{Conclusions}

Disparities regarding the economic and living standards between the member states of Northern and Western Europe compared to the Southern and Eastern Europe are reflected in municipal waste management systems with various environmental implications. The main measures to reduce the generated waste and the landfilling are the adoption of regulations and the economic instruments (charges for waste landfilling, taxes on the amount of waste generated), financial incentives, incentives to encourage waste producers to minimize waste etc. These measures are successfully adopted by western countries having a healthy economy which allow the best practices in waste management. Also, municipal waste management does not depend only on the income of the population; the sociodemographic factors and the implemented environmental policies may have a significant contribution to reducing or increasing the amount of waste generated. The quality and timeliness of data on waste statistics play an important role in waste management planning. The waste collection services of the new member states are poorly equipped to weigh the collected waste and often the reported values are calculated according to the volume of containers or transporting facilities.

The improvement of the waste management infrastructure and the orientation of the environmental policies towards waste prevention and reduction should be a real objective in the coming years for most EU members.

\section{Acknowledgements}

This work was supported by the European Social Fund in Romania, under the responsibility of the Managing Authority for the Sectoral Operational Programme for Human Resources Development 2007-2013 [grant POSDRU/CPP 107/DMI $1.5 / \mathrm{S} / 78342]$.

\section{References:}

Athanassiou, M., Zabaniotou, A. (2007), Techno-economic assessment of recycling practices of municipal solid wastes in Cyprus, Journal of Cleaner Production, 16, 1474-1483.

Beigl P., Lebersorger S., Salhofer S., (2008), Modelling municipal solid waste generation: A review, Waste Management, 28, 200-214

Burcea,S.G., (2009) - Managementul deşeurilor urbane: Perspectivă europeană comparată, Edit ASE, Bucureşti 
Davies,Anna, (2003) - Waste wars- public attitudes and the politics of place in waste management strategies ,Irish Geography, 36(1), 77-92

Den Boer, E., Jedrczak, A., Zygmunt K., Joanna Kulczycka, Szpadt, R., (2010) - A review of municipal solid waste composition and quantities in Poland, Waste Management, 30, 369-377

Fahy, F., Anna Davies. (2007) Home improvements: Household waste minimisation and action research, Resources, Conservation and Recycling, 52, 13-27

Husaini, G., Garg A., Kim K.H., Marchant, J., Pollard., S.J.T., Smith R., (2007) European household waste management schemes: Their effectiveness and applicability in England, Resources, Conservation and Recycling, 51, 248-263

Magrinho, A., Didelet, F., Semiao V., (2006) - Municipal solid waste disposal in Portugal , Waste Management ,26, 1477-1489

Mazzanti, M., Zoboli,R., (2008) -Waste generation, waste disposal and policy effectiveness Evidence on decoupling from the European Union, Resources, Conservation and Recycling, 52, 1221-1234

Mengozzi, A., (2010) - Waste Growth Challenges Local Democracy. The Politics of Waste between Europe and the Mediterranean: a Focus on Italy, California Italian Studies Journal, 1(1), 1-21 (http://escholarship.org/uc/item/53v28242)

Papaioannou, M., Economopoulou, A., 2004. Hellenic ministry for the environment, Physical planning and public works, Department of International Relations and EU Affairs. In: Proceedings of the National Reporting to the Twelfth Session of the Commission on Sustainable Development of the United Nations (UN CSD 12), Athens.

Perkoulidis G., Papageorgiou,A.,Karagiannidis, A., Kalogirou, S., (2010) - Integrated assessment of a new Waste-to-Energy facility in Central Greece in the context of regional perspectives, Waste Management, 30, 1395-1406

Sokka, L., Antikainen, R., Pekka, Kauppi E., (2007) Municipal solid waste production and composition in Finland-Changes in the period 1960-2002 and prospects until 2020, Resources, Conservation and Recycling, 50, 475-488

*** EC 2005 - Waste generated and treated in Europe Data 1995-2003, Luxembourg, Office for Official Publications of the European Communities

*** Eurostat 2001 - The development of waste indicators at European Union level: some recent Eurostat experiences, Joint ECE/Eurostat Work Session on Methodological Issues of Environment Statistics (Ottawa, Canada, 1-4 October 2001

*** (2008), OECD - Environmental Data, Compendium 2006-2008, Waste chapter.

*** (2005) UNEP - Solid Waste Management (Volume II: Regional Overviews and Information Sources) CalRecovery, Inc. California 94520 USA. 